\title{
Determining the extinction cross section of aggregating fish
}

\author{
Kenneth G. Foote, Egil Ona, and Reidar Toresen \\ Institute of Marine Research, 5024 Bergen, Norway
}

(Received 23 September 1991; accepted for publication 6 December 1991)

\begin{abstract}
When fish are aggregated over a flat bottom, and fish and bottom echoes can be distinguished, it is possible to determine the fish extinction cross section by a simple application of the echo integration method. The theory for this is developed. Measurements at $38 \mathrm{kHz}$ are presented for aggregations of the same 1983-year class of herring over flat-bottomed fjord areas in 1988, 1990, and 1991. The ratio of extinction and backscattering cross sections is found to lie in the approximate range from 1.2-2.3, depending on fish size and time of day.
\end{abstract}

PACS numbers: 43.30.Xm, 43.30.Pc, 43.30.Ft, 43.30.Gv

\section{INTRODUCTION}

Interest in extinction of underwater sound by biological scatterers has had several sources. One has recognized the need to account for biological effects in other kinds of acoustic measurements, ${ }^{1}$ for example, to understand fluctuations in long-range transmissions. Another has attempted to exploit the attenuation part of short-range fluctuations to measure fish density in fish-farming pens. ${ }^{2}$ A third source has aimed to correct measurements of fish density in dense or extended aggregations of fish. ${ }^{3}$ In most cases, swimbladderbearing fish have been the targeted scatterer type.

The three sources of interest have spawned a variety of measurements, which have yielded or might yield values for the extinction cross section of fish. Davies has measured attenuation of sound due to the northern anchovy (Engraulis mordax) confined in a Plexiglas sphere over the frequency range $1-20 \mathrm{kHz}^{4}$

A number of Japanese researchers has measured the extinction of sound due to fish aggregations by means of hydrophone observations of the transmitted waveform before and after passage through penned aggregations of fish. Measured fish species have included Japanese anchovy (Engraulis japonicus) at $50 \mathrm{kHz}$ by Hashimoto in 1955 and Maniwa in 1962, cited by Ishii et al. in 1983, ${ }^{5}$ sea bream (Chrysophrys major) and yellowtail (Seriola quinqueradiata) at $50 \mathrm{kHz},{ }^{2}$ and recently sea bream (Pagus major), spotted mackerel (Scomber australasicus), and yellowtail at 25, 50, 100, and $200 \mathrm{kHz}^{6}$

Røttingen has measured the echo energy from encaged aggregations of sprat (Sprattus sprattus), saithe (Pollachius virens), and mackerel (Scomber scombrus) at 38 and 120 $\mathrm{kHz} .^{7}$ An underwater acoustics research group in Norway has made simultaneous observations of the echo intensity from an aggregation of herring (Clupea harengus) and from the underlying flat, sandy seabed at $38 \mathrm{kHz}$, which were analyzed at the University of Birmingham. ${ }^{8}$ More recently, Toresen has made similar measurements, but with integration of the echo intensity over the entire ranges of the respective fish aggregation and bottom echoes. ${ }^{9}$ A Scottish research group has employed this reference-target technique in several variants on encaged aggregations of herring at 38 $\mathrm{kHz},{ }^{10}$ and on encaged aggregations of cod (Gadus morhua) at 38 and $120 \mathrm{kHz}$ and on a dense aggregation of hibernating herring in situ at $38 \mathrm{kHz} .{ }^{11}$

The various measurements have been aided by theoretical analyses. Weston derived an expression for the extinction cross section in terms of fundamental physical properties of a swimbladdered fish, modeled as an ellipsoidal air bubble, ${ }^{1}$ which extended Andreeva's basic spherical air-bubble model. ${ }^{12}$ Analysis of R $\phi$ ttingen's purely backscattered data has allowed determination of the extinction cross section through a parameter-fitting exercise. ${ }^{13}$ Measurements of the herring aggregation and underlying flat bottom described in Ref. 8 might have yielded a value for the extinction cross section, but the authors, Ertugrul and Smith, were more interested in examining the phenomenon of multiple scattering. However, for measurements of fish at ultrasonic frequencies, multiple scattering effects are entirely negligible. $^{14,15}$ Toresen has proved severe shadowing effects in dense herring schools, while using these quantitatively to derive an empirical factor for correcting the apparent measurements of fish density. ${ }^{9}$ The extinction cross section was not separated from this factor. Both Refs. 8 and 9 show a recognition of the usefulness of simultaneous observations of fish aggregation and bottom echoes. A similar recognition has been made by Hay for measuring the attenuating effect of suspended matter near the seabed. ${ }^{16}$

The usefulness of combined echo measurements of fish aggregations and bottom has also been clearly recognized in the cited Scottish work. ${ }^{10,11}$ This has employed spherical targets suspended beneath the fish aggregations in addition to the bottom echo in order to determine the extinction cross section. The work does suffer, however, from two limitations. One is a bias incurred whenever the data include cases of substantial extinction, when the reference target echo is relatively weak. Because of the use of the logarithmic measure of reference-target echo energy in the analysis, weak reference-target echoes are disproportionately weighted. In the limit of total extinction, the weight is negative infinity. The second problem is evident from the way in which the extinction cross section is determined, by regressing the logarithm of reference-target echo energy on the product of number density and mean backscattering cross section of the scatterer. In the absence of extinction, this product is just the area backscattering coefficient. In the presence of extinction, 
however, this product can only be derived from the measured coefficient by compensating for the unknown effect of extinction, which is being determined. Even if this can be done iteratively, as stated by the authors of Ref. 11, the algorithm they give is erroneous.

In this paper, a simpler and more general theory is presented. This enables the extinction cross section of scatterers in an aggregation to be determined from their echo together with the echo from a reference target under the aggregation. This is applied to a series of measurements on large and dense aggregations of herring hibernating in a fjord with flat bottom areas.

\section{THEORY}

Measurement of fish and flat bottom is assumed to be made by a downward-looking, narrow-beam transducer. Transmission and reception is controlled by a calibrated echo sounder. Range compensation is effected according to the ordinary function used in echo integration, namely $20 \log r+2 \alpha r$, where $r$ is the range and $\alpha$ is the absorption coefficient. In terms of the elapsed time $t$ from signal transmission, $r=c t / 2$, where $c$ is the speed of sound.

The range-compensated signal is integrated in piecewise fashion over a succession of range intervals $\left\{\left(r_{i}, r_{i+1}\right)\right\}$. The range is assumed to be equivalent to the depth $z_{i}=r_{i}$ by assumption of a narrow, downward-looking transducer beam. The result of integration is a series of area or column backscattering coefficients $s_{a}\left(z_{i}, z_{i+1}\right) \cdot{ }^{17}$ These may be alternatively expressed through the mean volume backscattering coefficient $s_{v}\left(z_{i}, z_{i+1}\right)$ in each interval, which is the mean cumulative backscattering cross section of scatterers per unit sampled volume per ping. ${ }^{18}$ For sampling by a narrow-beam transducer, $s_{v}=s_{a}\left(z_{i}, z_{i+1}\right) /\left(z_{i+1}-z_{i}\right)$.

A layer of aggregating fish is imagined to be confined to the depth interval $\left[z_{1}, z_{2}\right]$, if only occupying a portion of this. No other significant scatterers are present between the transducer and fish layer or between the fish layer and seabed, or bottom. The bottom is assumed, moreover, to be flat and acoustically uniform in the region beneath the fish layer. If the vertical extent of the fish layer within $\left[z_{1}, z_{2}\right]$ is $\Delta z$ and the fish density $\rho$ is constant, then

$$
s_{v}=\rho \frac{\sigma_{b}}{4 \pi} \frac{1-\exp \left(-2 \rho \sigma_{e} \Delta z\right)}{2 \rho \sigma_{e} \Delta z},
$$

where $\sigma_{b}$ is the average backscattering cross section, and $\sigma_{e}$ is the average extinction cross section. This expression is also well known from lidar applications in the atmosphere. ${ }^{19}$

The extinction cross section $\sigma_{e}$ in Eq. (1) is the arithmetic mean of the average extinction cross sections in both downward and upward directions. For fish that are oriented with respect to the horizontal plane, these two directions correspond, respectively, to the dorsal and ventral aspects. The extinction cross section defined here is the appropriate quantity for application in echo integration surveys, as in the extinction correction algorithm presented in Ref. 15, although not elaborated there. For applications in which the transmitted waveform is monitored, as in fish pens, ${ }^{6}$ a oneway average extinction cross section is required.
The vertical extent $\Delta z$ of the fish layer is used in Eq. (1). This could be replaced by a larger quantity if embracing $\Delta z$. Equation (1) would still apply, but $s_{v}$ would be reduced in inverse proportion to the assumed vertical extent. The density would be similarly reduced, while the product $\rho \Delta z$ remains unchanged.

The result of integrating $s_{v}$ over the assumed depth interval, or indeed over an arbitrary interval if including the fish layer and excluding the bottom, is independent of the assumed vertical extent. This result is just the area backscattering coefficient associated with the fish layer,

$$
s_{a, F}=\left(\sigma_{b} / 8 \pi \sigma_{e}\right)\left[1-\exp \left(-2 \rho \sigma_{e} \Delta z\right)\right] .
$$

Integration of the bottom echo over its full extent in time yields a corresponding area backscattering coefficient $s_{a, B}$. If fish are present in the described layer, then the average intensity of the pressure wave is diminished by the factor $\exp \left(-\rho \sigma_{e, d} \Delta z\right)$ compared to that incident on the bottom in the absence of the layer. Here, $\sigma_{e, d}$ indicates the dorsalaspect part of $\sigma_{e}$. The bottom echo itself is diminished in its upward passage through the fish layer by a similar factor, $\exp \left(-\rho \sigma_{e, v} \Delta z\right)$, where $\sigma_{e, v}$ denotes the ventral aspect part of $\sigma_{e}$. Thus, in terms of the area backscattering coefficient of the bottom in the absence of fish, $s_{a, B_{0}}$,

$$
s_{a, B}=s_{a, B_{0}} \exp \left(-2 \rho \sigma_{e} \Delta z\right),
$$

where $\sigma_{e}$ is the aforementioned arithmetic mean of dorsaland ventral-aspect average extinction cross sections.

Simultaneous solution of Eqs. (2) and (3) yields the result

$$
s_{a, B}=s_{a, B_{0}}\left[1-\left(8 \pi \sigma_{e} / \sigma_{b}\right) s_{a, F}\right] .
$$

This form emphasizes the dependence of $s_{a, B}$ on extinction due to the fish layer.

Equation (4) also suggests how the problem of determining $\sigma_{e}$ can be addressed. Specifically, $s_{a, F}$ and $s_{a, B}$ can usually be measured pairwise over a range of values of $s_{a, F}$, if only because of variations in optical thickness $\rho \sigma_{e} \Delta z$ with observation point. Linear regression of $s_{a, B}$ on $s_{a, F}$ estimates the regression coefficients $\alpha$ and $\beta$ in

$$
s_{a, B}=\alpha+\beta s_{a, F} .
$$

The extinction cross section is conveniently expressed through its ratio with the backscattering cross section,

$$
\sigma_{c} / \sigma_{b}=-\hat{\beta} /(8 \pi \hat{\alpha}),
$$

where $\hat{\alpha}$ and $\hat{\beta}$ are the estimated regression coefficients.

In practice, almost any fish layer will span a range of optical thicknesses, hence, values of $s_{a, F}$. By choosing sufficiently short intervals of sailed distance or sufficiently small numbers of successive pings to be combined in computing $s_{a, F}$ and $s_{a, B}$, at least a partial range of values of $s_{a, F}$ may be measured. In the very special case of an essentially uniform fish aggregation of constant optical thickness, the range in values of $s_{A, F}$ will be negligible or quite small, rendering regression analysis futile. Indeed, it is important that the observations span a range of optical thicknesses, since the quality of the result is generally directly related to the range of values spanned by the independent variable, $s_{a, F}$ here; being better for wider ranges. 
The range of values of $s_{a, F}$ may be further extended by observing the bottom echo in the absence of a covering fish layer. This would be crucial in the rare case of an essentially uniform fish aggregation. However, to use bottom-only data, for which $s_{a, F}=0$ and $s_{a, B}=s_{a, B_{0}}$, the bottom state must be the same as beneath the fish layer. Specifically, the bottom flatness and acoustic uniformity that apply beneath the fish layer must also apply in the absence of the fish.

The present formulation is nominally concerned only with extinction by a layer of aggregating fish over a flat bottom. It applies equally well to other scatterers in a layer and to other reference targets than a flat bottom. Thus a standard spherical target suspended beneath, or behind, a layer could also serve as the reference necessary for deducing the extinguishing effect of scatterers in the layer.

\section{MEASUREMENTS}

The primary measurement object is the 1983-year class of herring (Clupea harengus). This has been measured in Ofotfjord in northern Norway, Fig. 1, over a period of years.
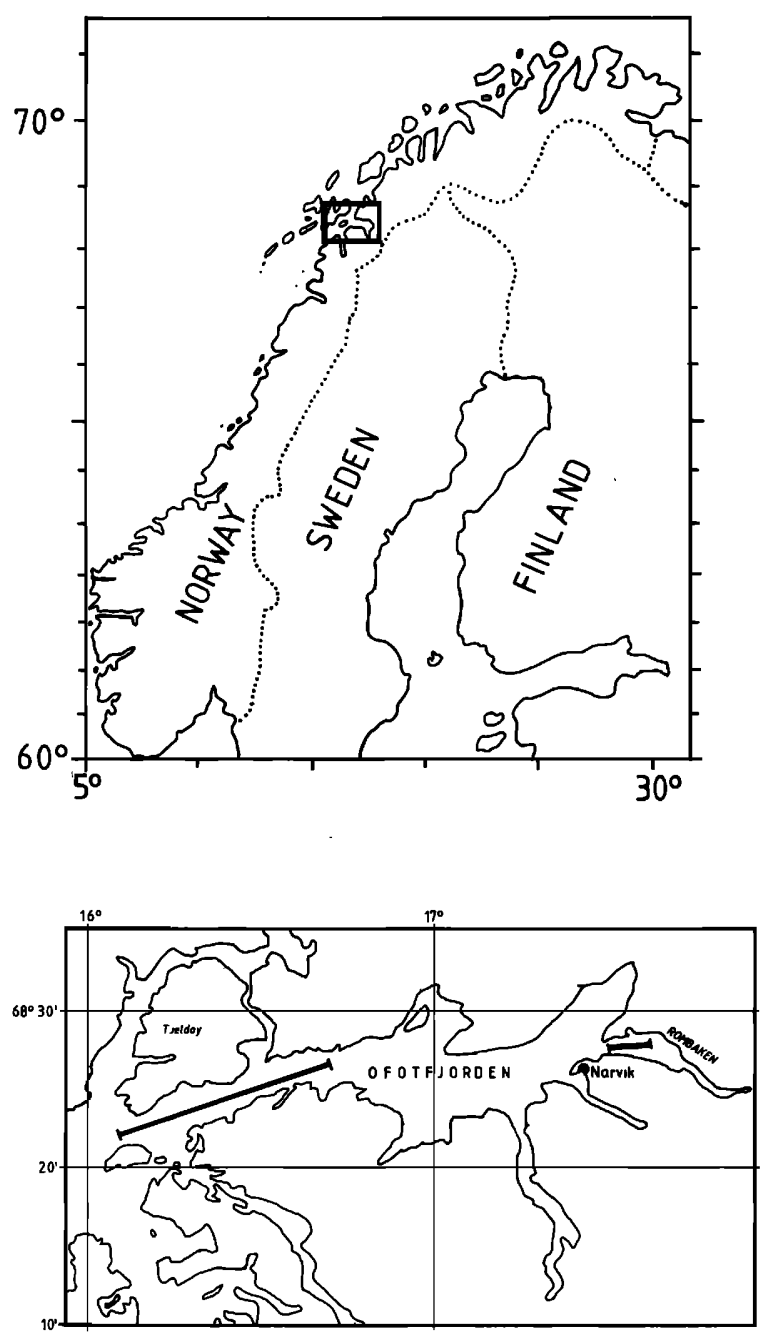

FIG. 1. Sites of data collection.
In particular, it has been measured in the hibernating state in the winters of 1988, 1990, and 1991. It often forms a quite dense and distinct layer in mid-water, sometimes also extending over flat-bottomed areas of the fjord, indicated by the thick lines in Fig. 1. In 1988, the herring was measured over the shorter, inner-fjord track, with bottom depth of 350 m. In 1990 and 1991, the herring was measured over the longer, outer-fjord track, with bottom depth of $540 \mathrm{~m} .{ }^{9}$ Based on the appearance of the echograms, the conditions for applying the measurement method described in Sec. I were fulfilled.

The precise unit of measurement is the area backscattering coefficient $s_{A}$, as defined by Knudsen. ${ }^{20}$ This refers the mean cumulative backscattering cross section in square meters to one square nautical mile (NM), hence, $s_{A}$ $=4 \pi 1852^{2} s_{a}$.

An exemplary echogram is shown in Fig. 2. The data were collected on 14 January 1990 under night-time conditions along the outer-fjord track indicated in Fig. 1. The displayed depth range is $100-600 \mathrm{~m}$. Echo integration was performed under very similar conditions over a 5-NM interval of sailed distance, which included the current, roughly 2NM interval shown in Fig. 2. Average values of the area backscattering coefficient for the herring layer and bottom, applicable over the entire 5-NM interval, are, respectively, $106000 \mathrm{~m}^{2} / \mathrm{NM}^{2}$ and $961000 \mathrm{~m}^{2} / \mathrm{NM}^{2}$. The area backscattering coefficient due to other fish and plankton is less than $100 \mathrm{~m}^{2} / \mathrm{NM}^{2}$.

Two different acoustic systems operating at $38 \mathrm{kHz}$ were used in the course of the measurements. In 1988, the SIMRAD EK400 echo sounder ${ }^{21}$ was used on board R/V ELDJARN together with the Institute's digital echo integrator based on the Norsk Data ND-10 computer. The receiving sensitivity of the echo sounder was reduced, relative to normal operation, by means of an attenuator in order to avoid saturation due to echoes from either the herring layer or bottom. In 1990 and 1991, the SIMRAD EK500 echo sounding system ${ }^{22}$ was used on board R/V MichaEl SARS. Because of the large dynamic range of this second system, nominally $160 \mathrm{~dB}$, there was no danger of receiver saturation, and the instrument operation was normal in all respects.

Both systems were operated with hull-mounted transducers resonant at $38 \mathrm{kHz}$. The nominal beamwidth between opposite - 3-dB levels is $8.0 \mathrm{deg}$ for the EK400 transducer used in 1988 and 7.0 deg for the EK500 transducer used in 1990 and 1991. The acoustic systems were calibrated according to the standard-target method recommended by the International Council for the Exploration of the Sea. ${ }^{23}$ The particular calibration target was a 60 -mm-diam solid copper sphere, with nominal target strength of $-33.6 \mathrm{~dB}$ at 38 $\mathrm{kHz}$.

Vessel speeds of 3,6, and $10 \mathrm{kn}$ were used during the measurements in 1988, without apparent difference in echo data. The nominal vessel speed during the measurements in 1990 and 1991 was $10 \mathrm{kn}$. Since the integration interval was typically one cable length, or $0.1 \mathrm{NM}$, estimates of the mean area backscattering coefficient were based on at least 36 pings. These were derived in pairwise fashion from echoes 

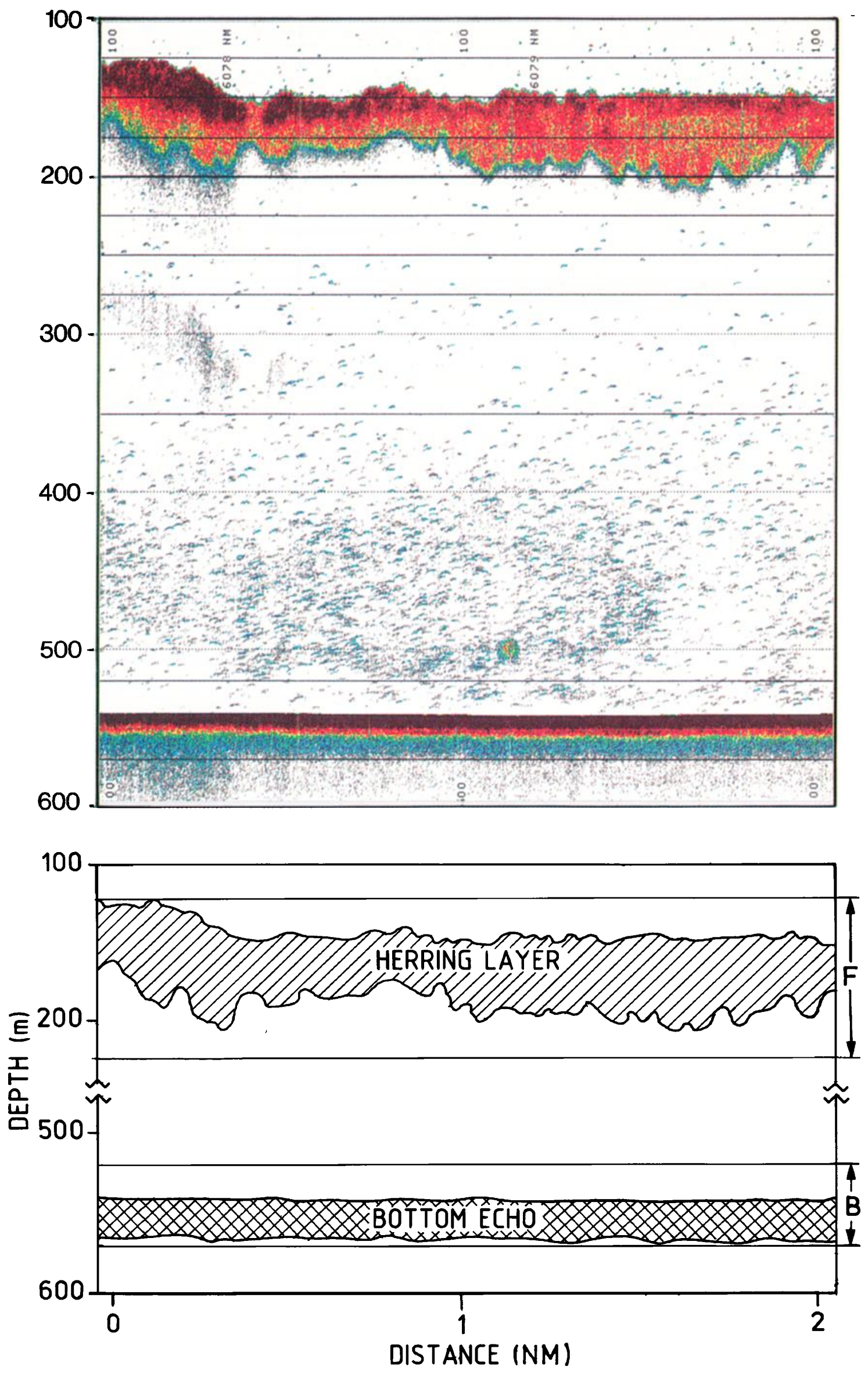

FIG. 2. Exemplary echogram with illustrative sketch showing a herring layer in outer Ofotfjord, under night-time conditions on 14 January 1990 . The symbols " $F$ " and " $B$ " in the right margin of the sketch indicate the integration limits for fish and bottom echoes. 
from both the fish layer and bottom for each ping.

Measurements were made in early January in each of the three years. The sun does not rise at this time, but a period of twilight extends over the hours 1000-1400. Night conditions prevail otherwise, barring possible periods with strong moonlight.

Data on fish size have been gathered by trawling with the standard pelagic "Harstad" trawl, which is otherwise known as a capelin trawl, with $16 \times 16$ fathoms opening. The sampled fish aggregations were composed entirely of herring, mainly of the 1983-year class, but with admixture of other year classes according to the data in Table I. Included in this table is the mean fish length.

\section{DATA ANALYSIS}

Sets of data for each year were separated into daytime and night-time subsets. A total of six subsets of data were thus available for statistical analysis. Two of these were rejected for covering only a narrow range of low fish densities, with maximum $s_{A, F}$ of about $10^{5} \mathrm{~m}^{2} / \mathrm{NM}^{2}$. Data with vanishing, or zero, values of $s_{A, F}$ were purged from the sets in order to relate the bottom echo data as much as possible to the extinction-causing fish layer. The resulting four sets of data are shown through the scatter diagrams of Fig. 3. Included with each is the least-mean-squares regression curve and its $95 \%$ confidence interval.

The linear regression analysis indicated in Eq. (5) is performed in terms of $s_{A}$ instead of $s_{a}$; i.e.,

Thus

$$
s_{A, B}=\alpha^{\prime}+\beta^{\prime} s_{A, F} .
$$

$$
\sigma_{e} / \sigma_{b}=-1852^{2} \hat{\beta}^{\prime} /\left(2 \hat{\alpha}^{\prime}\right) .
$$

Confidence intervals were attached to this estimate by observing that the ratio $-\alpha^{\prime} / \beta^{\prime}$ describes the value of $s_{A, F}$ for which $s_{A, B}=0$, i.e., for which extinction is total. This maximum value is itself uncertain insofar as the data do not lie exactly on a straight line. The confidence interval for the value of $\left(s_{A, F}\right)_{\max }$ may be derived by inverse prediction using Eq. (7a) with $s_{A, B}=0 .{ }^{24}$ Bounds on $\left(s_{A, F}\right)_{\max }$ can be computed for the mean of a large number of estimates of $\left(s_{A, F}\right)_{\max }$. The bounds are used in Eq. (7b) to assign limits to the ratio $\sigma_{e} / \sigma_{b}$. This has been done according to simple linear regression analysis.

TABLE I. Percentage composition of the herring 1983-year class, mean length $l$, associated standard error SE, and mean mass $m$, based on $n_{\mathrm{s}}$ samples, arranged by year of observation.

\begin{tabular}{cccccc}
\hline \hline Year & $\begin{array}{c}\text { Percentage } \\
\text { composition }\end{array}$ & $\begin{array}{c}l \\
(\mathrm{~cm})\end{array}$ & $\begin{array}{c}\text { SE } \\
(\mathrm{cm})\end{array}$ & $\begin{array}{c}m \\
(\mathrm{~g})\end{array}$ & $n_{\mathrm{s}}$ \\
\hline 1988 & 96.8 & 30.9 & 0.12 & 200 & 100 \\
1990 & 91.3 & 32.9 & 0.10 & 309 & 123 \\
1991 & 82.9 & 34.3 & 0.13 & 326 & 300 \\
\hline \hline
\end{tabular}

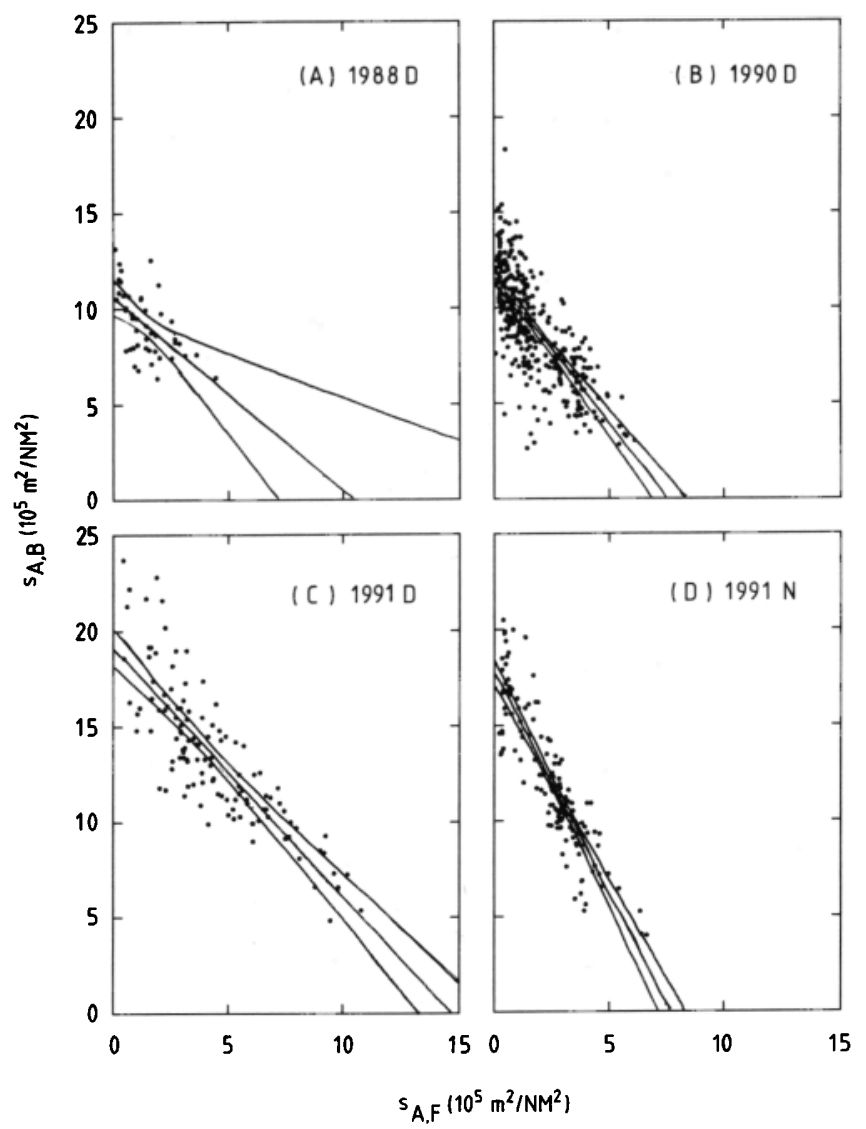

FIG. 3. Scatter diagrams of the data pair $\left(s_{A, F}, s_{A, B}\right)$, for fish and bottom echoes, respectively, for each of the four data sets, distinguished by year or time of day ( $\mathrm{D}=$ day or $\mathbf{N}=$ night $)$. The least-mean-squares regression of $s_{A, B}$ on $s_{A, F}$ is shown together with its $95 \%$ confidence interval.

\section{RESULTS AND DISCUSSION}

Some details of the linear regression analyses are presented in Table II. These are the estimated coefficients $\hat{\alpha}$ and $\hat{\beta}$ and the standard error SE of the regression. The estimate of the ratio $\sigma_{e} / \sigma_{b}$ is shown together with its $95 \%$ confidence limits $\left(\sigma_{e} / \sigma_{b}\right)_{-}$and $\left(\sigma_{e} / \sigma_{b}\right)_{+}$.

The mean values of $\sigma_{b}$ and $\sigma_{e}$ are also shown in Table II. These assume that the mean backscattering cross section is given by the following equation for the target strength: ${ }^{25}$

$$
\text { TS }=20 \log l-71.9=10 \log \left(\sigma_{b} / 4 \pi\right),
$$

where $l$ is the mean fish length in units of centimeters, given in Table $\mathrm{I}$, and $\sigma_{b}$ is expressed in units of square meters. This equation is currently used in stock assessment work to specify $\sigma_{b}$ for Atlanto-Scandinavian herring.

The mean estimates for $\sigma_{e} / \sigma_{b}$ for 1990D and $1991 \mathrm{~N}$ are essentially the same. The mean estimate for 1991D is significantly lower, but with similar $95 \%$ confidence interval of about $\pm 10 \%$ of the mean. The mean estimate for 1988D is intermediate, but its confidence interval overlaps those of the other estimates. This is understandable, for the number of data pairs in the 1988D set is only 45. 
TABLE II. Results of the linear regression analysis of $s_{A, B}$ on $s_{A, F}$ according to Eq. (7a), including estimated value for the ratio $\sigma_{e} / \sigma_{b}$, with $95 \%$ confidence limits, assumed value for $\sigma_{b}$, and computed value for $\sigma_{e}$. The units of $\sigma_{b}$ and $\sigma_{e}$ are square centimeters.

\begin{tabular}{ccccccccccc}
\hline \hline Year & $\mathrm{D} / \mathrm{N}$ & $\hat{\alpha}^{\prime}$ & $\hat{\beta}^{\prime}$ & $\mathrm{SE}$ & $n_{\mathrm{s}}$ & $\sigma_{e} / \sigma_{b}$ & $\left(\sigma_{c} / \sigma_{b}\right)_{-}$ & $\left(\sigma_{e} / \sigma_{b}\right)_{+}$ & $\sigma_{b}$ & $\sigma_{e}$ \\
\hline 1988 & $\mathrm{D}$ & 1059 & -1.012 & 144 & 45 & 1.64 & 0.97 & 2.24 & 7.7 & 12.7 \\
1990 & $\mathrm{D}$ & 1162 & -1.548 & 191 & 324 & 2.28 & 2.10 & 2.46 & 8.8 & 20.0 \\
1991 & $\mathrm{D}$ & 1916 & -1.304 & 204 & 120 & 1.17 & 1.06 & 1.26 & 9.5 & 11.2 \\
1991 & $\mathrm{~N}$ & 1778 & -2.320 & 169 & 140 & 2.24 & 2.10 & 2.37 & 9.5 & 21.4 \\
\hline \hline
\end{tabular}

The reasons for the close agreement of the 1990D and $1991 \mathrm{~N}$ values and for their significant difference with the 1991D value are unknown, as is the reason for the particular magnitudes. It is not, however, difficult to understand why the values might be different. A primary cause may be that of behavior. Studies on the relationship of mean backscattering cross section $\sigma_{b}$ to the fish orientation distribution shows that $\sigma_{b}$ does vary systematically with changes in orientation distribution. ${ }^{26,27}$ The extinction cross section $\sigma_{e}$ is expected to be less sensitive, for it consists principally of the total scattering cross section, with greater degree of implicit averaging than that in $\sigma_{b}$. Unfortunately, too little is known about the orientation distribution of fish in situ to speculate further on the present data, although it is conceivable that a theoretical study might permit inference of the orientation distribution, as in Ref. 28.

There are other sources of variability in the data that should be acknowledged, although the authors do not believe that these are responsible for the basic differences in estimates of $\sigma_{e} / \sigma_{b}$. (1) The four data sets were collected over a three-year period, during which the predominant 1983-year class matured. In addition to increasing in length, as documented in Table I, other acoustically significant properties of the animal may have changed. (2) Variations in the bottom, both in local flatness, local slope, and acoustic properties, may explain some of the dispersion of the data in Fig. 3, without, however, significantly affecting the mean regression estimate. The bottom appeared to be quite uniform according to the echogram, but the major region of bottom ensonification is quite large. For an 8-deg beam at $350 \mathrm{~m}$, for instance, this area is about $1800 \mathrm{~m}^{2}$, which suggests the coarseness of the echogram. (3) The density of herring in the aggregation did vary with depth, but in the worst observed instance, only by a factor of about 2.8 between minimum and peak density values in an 80-m-thick layer divided into eight sublayers. ${ }^{9}$ The minimum was observed at an edge, and the other measured density values were more uniform, with approximate range of variation of $\pm 10 \%$. Correction of these for extinction would increase the range of variation significantly, perhaps to $\pm 15 \%$, but, it is believed, without significant violation of the hypothesis of a uniform layer. In any case, the extinction cross section of fish in an aggregation may simply be defined according to Eq. (1), without regard to the constancy of or degree of variation in density with depth.

Vessel-specific differences might be discounted from consideration, for the value $\sigma_{e} / \sigma_{b}$ from R/V ELDJARN, a fishing vessel converted to research use, is intermediate to the values from R/V MichaEL SARS, which was built specifically for acoustic sampling. Vessel speed may also be discounted as an influencing factor, because of the negative results obtained during the experiments performed on $R / V$ ElDJARN at 3, 6, and $10 \mathrm{kn}$ in 1988 . The herring indeed appear to be in a quiescent state at this time of year, and insensitive to vessel passage.

It is interesting to compare the present results with other measurements on herring at $38 \mathrm{kHz}$. Armstrong et al. measured caged herring of $26-\mathrm{cm}$ length, with result for $\sigma_{e} / \sigma_{b}$ of $3.3 \pm 1.3 .^{10}$ MacLennan et al. report a value for in situ herring of 33-cm length of $1.4 \pm 0.3,{ }^{11}$ although the quality of this result is unknown, for reasons given in the Introduction. The in situ measurements were made from R/V Mrchael Sars at night in December 1989, in a fjord north of Ofotfjord, but containing the same 1983-year class that was observed again, under daylight conditions, in January 1990. From Table II, the 1990D measurements are seen to be significantly higher, namely $2.3 \pm 0.2$. The fact that the day-night difference is exactly reversed in 1991 highlights the state of ignorance about $\sigma_{e} / \sigma_{b}$.

The new series of measurements reported here will be continued in the future, but with collection of additional data. These may involve ping-by-ping recording of the depth dependence of the mean volume backscattering coefficient, use of a focusing sphere ${ }^{29}$ suspended beneath the fish layer to serve as a more stable reference target, and closer attention to light levels. The fat content of the fish may also be measured, in order to assess the state of the swimbladder. ${ }^{30} \mathrm{Giv}$ en better understanding of the nature of $\sigma_{e}$, acoustic estimates of density may be corrected according to the algorithm described in Ref. 15.

\section{SUMMARY}

A simple and robust theory for determining the extinction cross section of aggregating fish has been developed. The principal requirement for applying this is that the fish be confined to a layer that is clear of a more or less flat and acoustically uniform seabed, or bottom. Given this condition, the procedure for determining the extinction cross section consists of the following steps: (1) measurement of the area backscattering coefficients of fish layer and bottom in pairwise fashion and with sufficient resolution along the survey track to differentiate regions of varying degrees of extinction; (2) linear regression of the bottom coefficient on 
the fish layer coefficient to minimize the mean-square error; (3) computation of $\sigma_{e}$ from Eq. (6) or (7b) or like, depending on the units used for the area backscattering coefficient, assuming a value for $\sigma_{b}$; and (4) estimation of associated confidence limits of $\sigma_{e} / \sigma_{b}$ or $\sigma_{e}$ according to inverse prediction, observing that $\sigma_{e} / \sigma_{b}$ is inversely proportional to the extrapolated value for the fish layer coefficient when the bottom coefficient vanishes.

The same theory applies to other scatterers and to other reference targets, discrete as well as extended. Thus, anticipated measurement of the lateral-aspect extinction cross section of schooling fish with a directional sonar beam, by means of a standard target suspended behind the school, also falls within the scope of the present theory.

The theory has been applied to acoustic measurements on dense aggregations of hibernating herring in a Norwegian fjord. Results for $\sigma_{e} / \sigma_{b}$ have been in the approximate range from 1.2-2.3. Significant day and night differences have been observed, but without showing a consistent pattern or suggesting particular reasons for the differences.

Further research on the extinction cross section is planned. The goal is sufficient knowledge about $\sigma_{e}$ so that values can be assigned in an algorithm to remove the biasing effect of extinction from conventional echo integration measurements of fish density.

'D. E. Weston, "Sound propagation in the presence of bladder fish," in Underwater Acoustics, edited by V. M. Albers (Plenum, New York, 1967), Vol. 2, pp. 55-88.

${ }^{2}$ M. Furusawa, K. Ishii, Y. Miyanohana, and Y. Maniwa, "Experimental investigation of an acoustic method to estimate fish abundance using culture nets," Jpn. J. Appl. Phys. 23 (S23-1), 101-103 (1984).

${ }^{3}$ I. Røttingen, "On the relation between echo intensity and fish density," Fiskeridir. Skr. Ser. Havunders. 16, 301-314 (1976).

${ }^{4}$ I. E. Davies, "Attenuation of sound by schooled anchovies," J. Acoust. Soc. Am. 54, 213-217 (1973).

${ }^{5}$ K. Ishii, M. Furusawa, and Y. Miyanohana, "Measurements of attenuation of sound by schooling fish," Tech. Rep. Natl. Res. Inst. Fisheries Eng. Fishing Boat Instrum. 4, 73-94 (1983).

${ }^{6} \mathrm{M}$. Furusawa, K. Ishii, and Y. Miyanohana, "Attenuation of sound by schooling fish," J. Acoust. Soc. Am. submitted (1992).

${ }^{7}$ I. Røttingen, "Relasjoner mellom integrerte ekkointensiteter og fisketettheter," Cand. real. dissertation, University of Bergen, Bergen, Norway (1975).

${ }^{8}$ M. G. Ertugrul and B. V. Smith, "Multiple scattering effects in fish abundance estimation," Department of Electronic and Electrical Engineering
Memo. 492, University of Birmingham, Birmingham, England (1982).

${ }^{9} \mathbf{R}$. Toresen, "Absorption of acoustic energy in dense herring schools studied by the attenuation in the bottom echo signal," Fish. Res. 10, 317-327 (1991).

${ }^{10}$ F. Armstrong, E. J. Simmonds, and D. N. MacLennan, "Sound losses through aggregations of fish," Proc. IOA 11(3), 35-43 (1989).

${ }^{11}$ D. N. MacLennan, F. Armstrong, and E. J. Simmonds, "Further observations on the attenuation of sound by aggregations of fish," Proc. IOA 12(1), 99-106 (1990).

${ }^{12} \mathrm{I}$. B. Andreeva, "Scattering of sound by air bladders of fish in deep soundscattering ocean layers," Sov. Phys. Acoust. 10, 17-20 (1964).

${ }^{13} \mathrm{~K}$. G. Foote, "Analysis of empirical observations on the scattering of sound by encaged aggregations of fish," Fiskeridir. Skr. Ser. Havunders. 16, 423-456 (1978).

${ }^{14}$ T. K. Stanton, "Multiple scattering with applications to fish-echo processing," J. Acoust. Soc. Am. 73, 1164-1169 (1983).

${ }^{15} \mathrm{~K}$. G. Foote, "Correcting acoustic measurements of scatterer density for extinction," J. Acoust. Soc. Am. 88, 1543-1546 (1990).

${ }^{16}$ A. E. Hay, "Turbidity currents and submarine channel formation in Rupert Inlet, British Columbia. 1. Surge observations," J. Geophys. Res. 92(C3), 2875-2881 (1987).

${ }^{17}$ C. S. Clay and H. Medwin, Acoustical Oceanography: Principles and Applications (Wiley, New York, 1977).

${ }^{18}$ T. K. Stanton, R. D. M. Nash, R. L. Eastwood, and R. W. Nero, "A field examination of acoustical scattering from marine organisms at $70 \mathrm{kHz}$," IEEE J. Ocean Eng. 12, 339-348 (1987).

${ }^{19}$ R. C. Anderson and E. V. Browell, "First- and second-order backscattering from clouds illuminated by finite beams," Appl. Opt. 11, 1345-1351 (1972).

${ }^{20}$ H. P. Knudsen, "The Bergen Echo Integrator: an introduction," J. Cons. Int. Explor. Mer 47, 167-174 (1990).

${ }^{21}$ R. Brede, "Simrad EK400 scientific echo sounder," FAO Fish. Circ. 778, 44-56 (1984).

${ }^{22}$ H. Bodholt, H. Nes, and H. Solli, "A new echo-sounder system," Proc. IOA 11(3), 123-130 (1989).

${ }^{23}$ K. G. Foote, H. P. Knudsen, G. Vestnes, D. N. MacLennan, and E. J. Simmonds, "Calibration of acoustic instruments for fish density estimation: a practical guide," ICES Coop. Res. Rep. 144 (1987).

${ }^{24}$ N. R. Draper and H. Smith, Applied Regression Analysis (Wiley, New York, 1981), 2nd ed.

${ }^{25}$ K. G. Foote, "Fish target strengths for use in echo integrator surveys," J. Acoust. Soc. Am. 82, 981-987 (1987).

${ }^{26} \mathrm{O}$. Nakken and K. Olsen, "Target strength measurements of fish," Rapp. P.-v. Reun. Cons. Int. Explor. Mer 170, 52-69 (1977).

${ }^{27}$ K. G. Foote, "Effects of fish behaviour on echo energy: the need for measurements of orientation distributions," J. Cons. Int. Explor. Mer 39, 193-201 (1980).

${ }^{28} \mathrm{~K}$. G. Foote and J. J. Traynor, "Comparison of walleye pollock target strength estimates determined from in situ measurements and calculations based on swimbladder form," J. Acoust. Soc. Am. 83, 9-17 (1988).

${ }^{29}$ R. J. Urick, Principles of Underwater Sound (McGraw-Hill, New York, 1983), 2nd ed.

${ }^{30} \mathrm{E}$. Ona, "Physiological factors causing natural variations in acoustic target strength of fish," J. Mar. Biol. Assoc. U.K. 70, 107-127 (1990). 